\title{
Shift in Sensitivity of Alternaria solani in Response to $\mathbf{Q}_{\mathbf{0}} \mathbf{I}$ Fungicides
}

\author{
J. S. Pasche, C. M. Wharam, and N. C. Gudmestad, Department of Plant Pathology, North Dakota State \\ University, Fargo 58105
}

\begin{abstract}
Pasche, J. S., Wharam, C. M., and Gudmestad, N. C. 2004. Shift in sensitivity of Alternaria solani in response to $\mathrm{Q}_{0} \mathrm{I}$ fungicides. Plant Dis. 88:181-187.

Isolates of Alternaria solani, cause of potato early blight, collected in 1998 through 2001 from various potato growing areas across the midwestern United States, were tested for sensitivity to azoxystrobin. Isolates collected in 1998, prior to the introduction of azoxystrobin, were tested to establish the baseline sensitivity of the fungus to this fungicide. Isolates collected in subsequent years, not necessarily from the same sites as baseline isolates, were tested to determine if populations of A. solani had become less sensitive to azoxystrobin. Azoxystrobin sensitivity was determined utilizing an in vitro spore germination assay. The effective fungicide concentration that inhibited spore germination by $50 \%\left(\mathrm{EC}_{50}\right)$ was determined for each isolate. There was no significant difference in mean $\mathrm{EC}_{50}$ values between baseline isolates and all other isolates collected through 1999. Mean azoxystrobin $\mathrm{EC}_{50}$ values of $A$. solani isolates collected in 2000 and 2001 were significantly higher compared with means from previous years, and mean azoxystrobin $\mathrm{EC}_{50}$ values from 2001 were significantly higher than means from isolates collected in 2000. A subset of $54 \mathrm{~A}$. solani isolates was evaluated in vitro for cross-sensitivity to pyraclostrobin and trifloxystrobin. A highly significant and strong correlation among the isolates tested for fungicide cross-sensitivity was detected between azoxystrobin and pyraclostrobin; however, the correlation between azoxystrobin and trifloxystrobin, and between trifloxystrobin and pyraclostrobin, was significant but weak. A second subset of five isolates was chosen for in vivo assessment of azoxystrobin, pyraclostrobin, and trifloxystrobin sensitivity. Disease severity on plants treated with azoxystrobin and pyraclostrobin was significantly greater with reducedsensitive A. solani isolates compared with sensitive isolates. Disease severity was not statistically different between azoxystrobin reduced-sensitive and sensitive A. solani isolates on plants treated with trifloxystrobin. This is the first report of a shift in sensitivity to $\mathrm{Q}_{\mathrm{O}} \mathrm{I}$ fungicides in a fungus possessing only an anamorphic stage.
\end{abstract}

Additional keywords: reduced sensitivity, Solanum tuberosum

Potato early blight occurs worldwide and is prevalent wherever potatoes are grown. Alternaria solani Sorauer has long been recognized as a foliar pathogen of potato (Solanum tuberosum L.) and is considered to be a difficult pathogen to control (3), largely because few cultivars possess resistance (2). The most effective early blight control measure is frequent application of protectant fungicides from early in the growing season until vine desiccation (12).

Late in the 1998 growing season, North Dakota, Minnesota, Nebraska, and Wisconsin were granted emergency use labels for azoxystrobin (Quadris, Syngenta Crop Protection, Greensboro, NC) by the Environmental Protection Agency (EPA); full registration was granted in 1999. Initially, excellent early blight control was provided by this new chemistry; however, reduced

Corresponding author: Neil C. Gudmestad E-mail: neil.gudmestad@ndsu.nodak.edu

Accepted for publication 17 September 2003.

Publication no. D-2003-1119-01R

(C) 2004 The American Phytopathological Society disease control was first observed in isolated commercial potato fields in 2000. Quinol-oxidizing inhibitor $\left(\mathrm{Q}_{0} \mathrm{I}\right)$ fungicides, such as azoxystrobin, have a single site mode of action, interfering with the electron transport of the cytochrome $b_{1}$ complex (4). Related $Q_{0} I$ chemistries trifloxystrobin (Gem, Bayer Corporation, Agricultural Division, Kansas City, MO) and pyraclostrobin (Headline, BASF Corporation, Agricultural Products, Research Triangle Park, NC), registered for use on potato in 2001 and 2002, respectively, have the same mode of action as azoxystrobin.

Previous research indicated that a shift in sensitivity to azoxystrobin in field isolates of $A$. solani might have been detected as early as 1999 (5). Based on these preliminary results and field observations of inadequate early blight control by azoxystrobin, a study was conducted to determine if a shift in the sensitivity of $A$. solani to azoxystrobin has occurred. The specific objectives of the study were: the establishment of an in vitro baseline sensitivity distribution of $A$. solani isolates collected from commercial potato fields in 1998, prior to azoxystrobin registration and use; determination of in vitro azoxystrobin sensitivity of $A$. solani isolates collected in
1998, 1999, 2000, and 2001, subsequent to azoxystrobin registration; establishment of in vitro baseline sensitivity to pyraclostrobin and trifloxystrobin; and determination of the significance of the in vitro shift in sensitivity of $A$. solani to azoxystrobin, pyraclostrobin, and trifloxystrobin on disease control.

\section{MATERIALS AND METHODS}

Collection, isolation, and maintenance of A. solani. Isolates of A. solani were recovered from potato foliar and tuber tissue submitted to our laboratory from various areas throughout the midwestern United States. A. solani isolates tested from 1998 and 1999 were obtained via single spore isolation from hyphal tip cultures (5). Emergency use labels for azoxystrobin were granted and first applications were made after 30 July 1998 in Minnesota, North Dakota, Nebraska, and Wisconsin, and full label registration was not available in other states until 1999. Therefore, only isolates collected prior to these dates in each respective state were included in the baseline assessment. A total of 21 isolates, collected in 1998 after the emergency registration of azoxystrobin in Minnesota, North Dakota, Nebraska, and Wisconsin, were placed into a "1998 nonbaseline group." These isolates are included in a separate nonbaseline group because they were collected after azoxystrobin had been used in commercial potato fields during the 1998 growing season and we cannot discount the possibility that they were exposed to this fungicide. Isolates tested from 2000 and 2001 were obtained via single spore isolation directly from diseased tissue and transferred to petri plates containing clarified V8 medium (CV-8) (Campbell's V8 juice, $100 \mathrm{ml} ; \mathrm{CaCO}_{3}, 1.5 \mathrm{~g}$; agar, $15 \mathrm{~g}$; and distilled water, $900 \mathrm{ml}$ ). Isolates collected during each of the 4 years were not necessarily collected from the same sites within each state.

Isolates were preserved in long-term cryogenic storage. Each isolate was grown on CV-8 for 7 to 10 days under 24-h light at room temperature $\left(25 \pm 2^{\circ} \mathrm{C}\right)$ until the agar surface was covered with profuse mycelium and spores. Agar plugs with fungal mycelia and conidia were excised using a sterilized 4-mm cork borer. Plugs were placed in small screw-top centrifuge tubes and placed with loosened lids in the laminar flow hood for 24 to $48 \mathrm{~h}$ to remove moisture from the medium. The tubes were sealed with Parafilm and stored at $-80^{\circ} \mathrm{C}$. 
Herbarium specimens were also prepared from each tissue sample from which $A$. solani isolates originated.

In vitro assessment of $Q_{0} I$ sensitivity. An experiment was conducted to determine the effect of salicylhydroxamic acid at $100 \mu \mathrm{g} / \mathrm{ml}$ (SHAM) (Sigma Chemical Co., St. Louis, MO) on spore germination of A. solani (10). SHAM is frequently added to media to prevent the fungus from overcoming the toxicity of $\mathrm{a}_{\mathrm{O}} \mathrm{I}$ fungicide through an alternative oxidative pathway $(7,10,15)$. A stock solution of $10,000 \mu \mathrm{g} / \mathrm{ml}$ SHAM in methanol was prepared by adding $100 \mathrm{mg}$ of SHAM to every $1 \mathrm{ml}$ of methanol and warming in a $37^{\circ} \mathrm{C}$ water bath for 1 to $2 \mathrm{~min}$ to completely dissolve the SHAM. The final concentration of methanol in both amended and unamended media was $0.1 \%$ by volume. Thirty-one $A$. solani isolates, representing 1998 and 2001 isolate collections, were randomly selected, and conidia from these isolates were plated onto water agar with and without SHAM.

Technical formulations of azoxystrobin ( $95.3 \%$ a.i.), pyraclostrobin (93.5\% a.i.), and trifloxystrobin $(99.4 \%$ a.i. $)$ were dissolved in acetone (10.5, 10.7, and 10.1 $\mathrm{mg}$ of fungicide per $\mathrm{ml}$, respectively) to obtain stock solutions of $10,000 \mu \mathrm{g} / \mathrm{ml}$. Azoxystrobin sensitivity was determined by comparing spore germination on $1.5 \%$ water agar amended with $0.0,0.01,0.1$, 1.0 , and $10.0 \mu \mathrm{g} / \mathrm{ml}$ azoxystrobin and 100 $\mu \mathrm{g} / \mathrm{ml}$ SHAM (10). For cross-sensitivity assessments, azoxystrobin, pyraclostrobin, and trifloxystrobin sensitivities were determined by comparing spore germination on $2 \%$ water agar amended with $0,0.001$, $0.01,0.1,1.0$, and $10.0 \mu \mathrm{g} / \mathrm{ml}$ technical formulations of each fungicide and 100 $\mu \mathrm{g} / \mathrm{ml}$ SHAM. The final concentration of acetone in the media was $0.1 \%$ by volume.

Sterile distilled water containing 5 drops of Tween 20 (Sigma) per $100 \mathrm{ml}$ was added to $A$. solani cultures, and conidia were dislodged using a sterile glass rod. The concentration of the conidial suspension was adjusted to $1 \times 10^{5}$ conidia per $\mathrm{ml}$ using a hemacytometer, and $500 \mu \mathrm{l}$ of the conidial suspension of each isolate was added to two replicate plates of each fungicide dilution. The suspension was spread across each plate using a sterile glass rod. The plates were allowed to partially dry in a laminar flow hood for approximately 20 min. Each plate was sealed with Parafilm and held in a Precision incubator (GCA Corporation, Chicago, IL) with continuous light at $21^{\circ} \mathrm{C}$ for $4 \mathrm{~h}$. For the $\mathrm{Q}_{\mathrm{o}} \mathrm{I}$ crosssensitivity testing, a few changes were implemented into the technique in order to increase efficiency. These changes included the use of $2 \%$ laboratory grade agar (Fisher Scientific A360-500) and the omission of Tween 20 in the water used to prepare the spore suspension. A further modification to the spore germination assay was that petri plates were not dried or sealed with Parafilm prior to incubation. Plates not sealed with Parafilm dried sufficiently for clear examination of the spores during the 4-h incubation. After incubation, conidia were examined with a compound microscope at $\times 100$ magnification. A conidium was considered germinated if the germ tube was at least equal in length to the conidium or if there were multiple germ tubes developing normally from a single conidium.

The concentration that effectively reduces germination by $50 \%$ relative to the untreated control $\left(\mathrm{EC}_{50}\right)$ was determined for each isolate tested in the in vitro azoxystrobin sensitivity study. The mean number of conidia germinated for two replicates was converted into a percent reduction of germination relative to the untreated control. These data were regressed against the logarithm of the fungicide concentration, and the $\mathrm{EC}_{50}$ value was determined by interpolation of the $50 \%$ intercept.

A total of 180 A. solani isolates was evaluated within the azoxystrobin sensitivity assessment in 12 separate trials, 7 to 24 isolates per trial. Internal controls (isolates 13-1, sensitive to azoxystrobin, and 526-3, which is azoxystrobin reduced-sensitive) were included in each of the 12 trials to determine the reproducibility of the germinated spore test. The assay reproducibility calculations used by Wong and Wilcox (17) were applied to the internal control isolates. The assay reproducibility calculations generated the approximate limits for a $95 \%$ confidence interval for the two internal controls. These limits were approximated because the Land's Coefficients had to be estimated. Only those experiments in which the $\mathrm{EC}_{50}$ values of the internal controls were within the $95 \%$ confidence interval were included in further statistical analyses. Each isolate tested in an experiment was set in a completely randomized design with two replications per fungicide concentration. Fifty conidia were examined per replication. All experiments were performed twice. Based on $\mathrm{EC}_{50}$ values from the in vitro azoxystrobin sensitivity assessment, isolates were placed into two groups, azoxystrobin sensitive and azoxystrobin reduced-sensitive.

Trials were analyzed separately and an $F$ test was performed to test for homogeneity of variance among the experiments. The analysis was performed using the general linear models procedure on the mean $\mathrm{EC}_{50}$ values using the Statistical Analysis System (SAS Institute, Cary, NC). Further analyses were conducted using the combined $\mathrm{EC}_{50}$ values for the 32 baseline isolates compared with those with exposure to azoxystrobin, including the 21 isolates from 1998 not included in the baseline, the 11 isolates from 1999, the 13 isolates from 2000, and the 103 isolates from 2001. Mean $\mathrm{EC}_{50}$ values for each isolate were separated using the least significant differ- ence test (LSD, $P=0.05$ ). It is important to note that results for 2001 are biased as a consequence of isolates being collected primarily from fields in which azoxystrobin applications had yielded insufficient early blight disease control.

A subset of 54 A. solani isolates previously tested in vitro for sensitivity to azoxystrobin were tested in vitro for crosssensitivity among the $\mathrm{Q}_{0} \mathrm{I}$ fungicides azoxystrobin, pyraclostrobin, and trifloxystrobin. Isolates were chosen both by geographic location from which they originated and $\mathrm{EC}_{50}$ values obtained in the in vitro azoxystrobin tests. Twenty-six azoxystrobin sensitive $A$. solani isolates from 1998 were selected for the in vitro cross-sensitivity assessment, 25 of which had been tested previously in the in vitro azoxystrobin sensitivity experiments and were determined to have $\mathrm{EC}_{50}$ values within the range of the baseline isolates. Twenty-seven azoxystrobin reduced-sensitive isolates of $A$. solani from 2001 were selected, 22 of which had been determined previously to have $\mathrm{EC}_{50}$ values above the range established for the baseline isolates. An additional $A$. solani isolate was included that had an azoxystrobin $\mathrm{EC}_{50}$ value between the baseline and reduced-sensitive ranges.

Isolates were tested in 10 separate trials, 4 to 16 isolates per experiment. Control isolates were included in the first eight trials to ensure the results obtained from the new methods correlated with the previously established results. For each fungicide, $t$ tests were used to detect differences in the mean $\mathrm{EC}_{50}$ values between the azoxystrobin sensitive and azoxystrobin reduced-sensitive groups of isolates using the Statistical Analysis System. Correlation analysis was also performed on the $\mathrm{EC}_{50}$ values from azoxystrobin, pyraclostrobin, and trifloxystrobin in vitro crosssensitivity assessment using the Persons correlation coefficients as a measure of the relationships among the three fungicides.

Effect of isolate sensitivity to $Q_{0} I$ fungicides on disease control. A subset of five isolates of $A$. solani previously tested in vitro for sensitivity to azoxystrobin, pyraclostrobin, and trifloxystrobin were selected for an in vivo assessment to determine the effect of azoxystrobin reducedsensitivity on disease control provided by these three $\mathrm{Q}_{0} \mathrm{I}$ fungicides. The isolates were selected based on the $\mathrm{EC}_{50}$ values obtained in the in vitro cross-sensitivity test and on the geographic location where the isolates were obtained. The isolates were recovered from long-term storage, maintained, and conidia were harvested as described previously for the in vitro $\mathrm{Q}_{0} \mathrm{I}$ assessment.

The in vivo sensitivity assay for $A$. solani isolates was conducted as a $24-\mathrm{h}$ preventative test. Fungicides were applied $24 \mathrm{~h}$ prior to inoculation in the greenhouse using tomato plants, cv. Bonny Best (To- 
tally Tomatoes, Augusta, GA). Tomato plants were utilized for the in vivo study because of this cultivar's susceptibility to early blight. Also, as opposed to potatoes, their compact size allowed for adequate replication while evaluating multiple fungicides and fungicide concentrations across several A. solani isolates. Five tomato seeds were sown in each $10-\mathrm{cm}^{2}$ pot, in Sunshine Mix 1 (Sun Gro Horticulture Inc., Bellevue, WA) without additional fertilizer. When the first true leaves were nearly fully expanded, plants were removed to obtain three uniformly sized plants per pot. The three plants were treated with commercial formulations of azoxystrobin (Quadris), pyraclostrobin (Headline), or trifloxystrobin (Gem). Tenfold fungicide concentrations of each active ingredient were applied to plants $(0$, $0.1,1.0,10.0$, and $100.0 \mu \mathrm{g} / \mathrm{ml}$ ) to obtain a dose response curve for each $\mathrm{Q}_{\mathrm{O}} \mathrm{I}$ fungicide. Each fungicide was applied to runoff in such a manner as to completely and uniformly wet both the abaxial and adaxial leaf surfaces using a $\mathrm{CO}_{2}$-powered backpack sprayer at approximately 172 $\mathrm{kPa}$. Twenty-four hours after fungicide application, tomato plants were prewetted with distilled water applied using a hand sprayer and then inoculated with a $2.0 \times$ $10^{5}$ conidia per ml suspension from 12 - to 14-day-old cultures of an A. solani isolate using a Preval paint-spray gun (Preval Sprayer Division, Precision Valve Corporation, Yonkers, NY). The inoculated tomato plants were held in individual mist chambers $(>95 \%$ relative humidity $[\mathrm{RH}]$, 22 to $24^{\circ} \mathrm{C}$, $16-\mathrm{h}$ photoperiod) for $24 \mathrm{~h}$, after which plants were transferred to confinement chambers (plastic chambers with open ceilings) on greenhouse benches. The plants were watered once per day, and the temperature in the isolation chambers was maintained at approximately $24 \pm 2^{\circ} \mathrm{C}$.

The experiment was a split-plot randomized complete block design. Confinement chambers, used to reduce the potential for cross contamination among $A$. solani isolates, were treated as the main blocking factor. Fungicides at each concentration were treated as the split-plots. Seven to 14

Table 1. Mean in vitro conidial germination of Alternaria solani isolates in the presence and absence of salicylhydroxamic acid (SHAM) at $100 \mu \mathrm{g} / \mathrm{ml}$

\begin{tabular}{lcc}
\hline & \multicolumn{2}{c}{ \% Germination ${ }^{\mathrm{a}}$} \\
\cline { 2 - 3 } $\begin{array}{l}\text { Isolate } \\
\text { group }\end{array}$ & $\begin{array}{c}\text { Without } \\
\text { SHAM }\end{array}$ & With SHAM \\
\hline 1998 & $96.25(9.30)^{\mathrm{b}}$ & $97.94(4.05)$ \\
2001 & $98.59(3.01)$ & $97.89(3.01)$ \\
\hline
\end{tabular}

a No significant differences in \% germination were observed between the SHAM and without SHAM treatments with $1998(\mathrm{n}=7)(P=$ $0.3500)$ or 2001 isolate groups $(\mathrm{n}=24)(P=$ $0.1581)$.

${ }^{b}$ Values in parentheses denote standard deviation. days postinoculation disease severity was rated visually by estimating percent infected leaf area of the first two true leaves (two subsamples) and recorded as percent diseased tissue. Three replications (three pots) and three samples (three plants per pot) were tested for each isolate $x$ fungicide concentration. The experiment was performed three times. Levene's test (8) was conducted to test for homogeneity of variance among the three independent experiments at each fungicide concentration and between the two isolate groups (sensitive and azoxystrobin reduced-sensitive). For each fungicide concentration, disease severity data were transformed to percent disease control for further statistical analysis using the formula: [1 (\% diseased tissue $/ \%$ diseased tissue in untreated plants $) \times 100$ ]. The ANOVA was performed separately for each fungicide $\times$ isolate group combination at each fungicide concentration using the Statistical Analysis System, and $t$ tests were used on the combined data to detect differences at each fungicide concentration.

\section{RESULTS}

In vitro assessment of azoxystrobin sensitivity. Among the $31 \mathrm{~A}$. solani isolates tested, it was determined that 100 $\mu \mathrm{g} / \mathrm{ml}$ SHAM had no deleterious effects on spore germination (Table 1). Therefore, SHAM was used at the rate of $0.1 \%$ $\mathrm{vol} / \mathrm{vol}(100 \mu \mathrm{g} / \mathrm{ml})$ in all subsequent in vitro $Q_{0} I$ fungicide experiments.

Analysis of each in vitro azoxystrobin sensitivity experiment separately produced the error mean squares necessary to complete the $F$ test for homogeneity of variance; therefore, the data were combined for further analysis. Significant differences in $\mathrm{EC}_{50}$ values were detected among $A$. solani isolates grouped by year (Fig. 1). Nearly all of the isolates examined in the azoxystrobin assessment could be clearly classified into two groups. One group of 76 isolates, with $\mathrm{EC}_{50}$ values less than 0.10 $\mu \mathrm{g} / \mathrm{ml}$, was clearly sensitive to azoxystrobin and was designated "azoxystrobin sensitive." Azoxystrobin sensitive isolates were collected in 1998, 1999, 2000, and 2001 (Table 2). A total of $100 \mathrm{~A}$. solani isolates from 2000 and 2001 had $\mathrm{EC}_{50}$ values above $1.450 \mu \mathrm{g} / \mathrm{ml}$ and were designated as "azoxystrobin reducedsensitive" and are hereby referred to frequently as reduced-sensitive for the purpose of clarity. One A. solani isolate collected in 1999 with an $\mathrm{EC}_{50}$ value of $0.250 \mu \mathrm{g} / \mathrm{ml}$ and three $2001 \mathrm{~A}$. solani isolates with $\mathrm{EC}_{50}$ values of $0.775,0.700$, and $0.510 \mu \mathrm{g} / \mathrm{ml}$ were in a transition group between the obviously sensitive and reduced-sensitive groups (Table 2).

Sensitivity of A. solani to azoxystrobin among the 32 baseline isolates, expressed as $\mathrm{EC}_{50}$ values, ranged from 0.011 to 0.090 $\mu \mathrm{g} / \mathrm{ml}$ (Table 2), with a mean $\mathrm{EC}_{50}$ value of $0.038 \mu \mathrm{g} / \mathrm{ml}(\mathrm{SD}=0.023)$ (Fig. 1). $\mathrm{EC}_{50}$ values obtained for the $21 \mathrm{~A}$. solani isolates collected in 1998 after 30 July from states where emergency use registration of azoxystrobin was granted ranged from 0.020 to $0.077 \mu \mathrm{g} / \mathrm{ml}$ (Table 2), with a mean of $0.039 \mu \mathrm{g} / \mathrm{ml}(\mathrm{SD}=0.016)$, which is numerically higher than, but not significantly different from, the mean $\mathrm{EC}_{50}$ of the baseline isolates collected before azoxystrobin registration (Fig. 1). Eleven isolates collected from the 1999 growing season had a range of $\mathrm{EC}_{50}$ values from 0.031 to $0.250 \mu \mathrm{g} / \mathrm{ml}$ (Table 2), with a mean of $0.057 \mu \mathrm{g} / \mathrm{ml}(\mathrm{SD}=0.064)$, which also does not differ significantly from either the true baseline isolate group or the

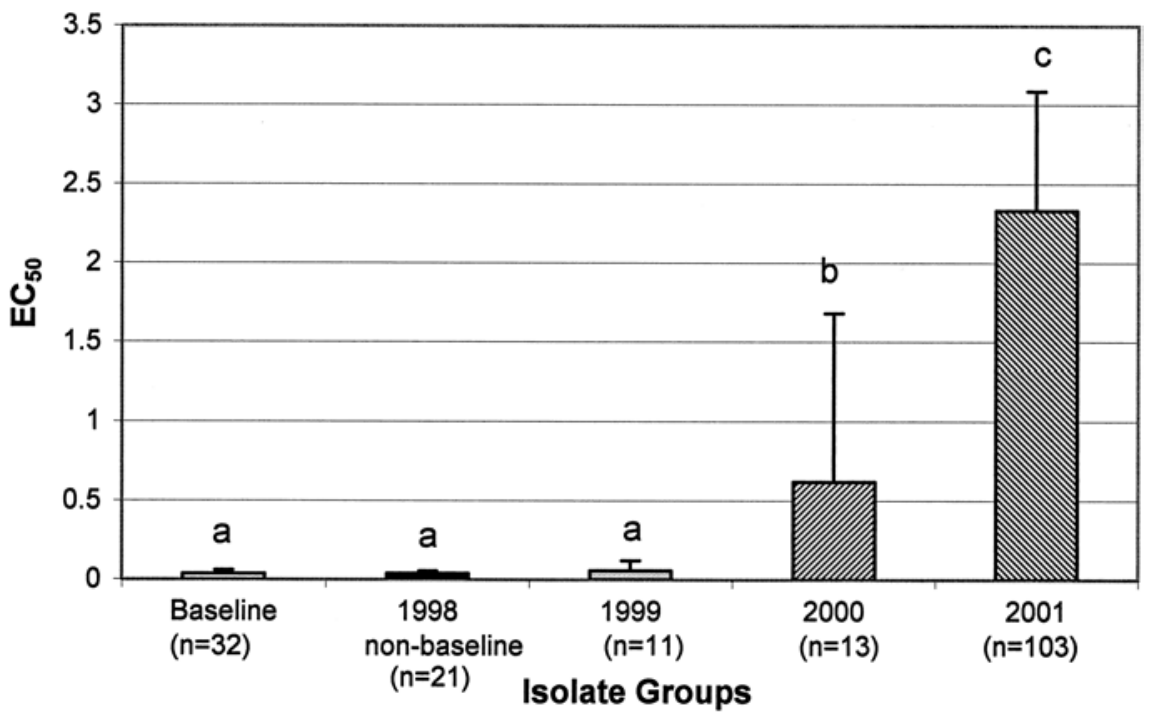

Fig. 1. Mean $\mathrm{EC}_{50}$ values (effective fungicide concentration that inhibited spore germination by $50 \%$ ) for Alternaria solani isolate groups obtained from the in vitro azoxystrobin assessment with mean separation based upon the least significant difference (LSD). Columns with the same letter are not significantly different $(P=0.05)$. Vertical bars indicate standard deviation for all tests performed on each isolate group. 
nonbaseline 1998 isolate group (Fig. 1). The 13 A. solani isolates tested from the 2000 growing season had a range of $\mathrm{EC}_{50}$ values from 0.032 to $2.550 \mu \mathrm{g} / \mathrm{ml}$ (Table 2 ), with a mean of $0.621 \mu \mathrm{g} / \mathrm{ml}(\mathrm{SD}=$ 1.062), which is significantly higher than the mean $\mathrm{EC}_{50}$ values obtained for the baseline, nonbaseline 1998, and 1999 isolate groups (Fig. 1). Among $100 \mathrm{~A}$. solani isolates assayed from 2001 , the $\mathrm{EC}_{50}$ values ranged from 1.210 to $3.400 \mu \mathrm{g} / \mathrm{ml}$ (Table 2), with a mean of $2.333 \mu \mathrm{g} / \mathrm{ml}$ (SD $=0.755$ ), which is significantly higher than any other group of $A$. solani isolates tested (Fig. 1). Three A. solani isolates obtained in 2001 were obtained from commercial potato fields in North Dakota in which azoxystrobin was effectively controlling

Table 2. Collection data and azoxystrobin assessment of $\mathrm{EC}_{50}$ values (effective fungicide concentration that inhibited spore germination by 50\%) of Alternaria solani isolates collected from fields in the 1998, 1999, 2000, and 2001 growing seasons from several states

\begin{tabular}{|c|c|c|c|c|}
\hline $\begin{array}{l}\text { State of origin of } \\
\text { A. solani isolates }\end{array}$ & No. of isolates & $\begin{array}{c}\text { Azoxystrobin } \\
\text { exposures }\end{array}$ & $\begin{array}{c}\text { Mean EC } \\
(\mu \mathrm{g} / \mathrm{ml})\end{array}$ & $\mathrm{EC}_{50}$ range \\
\hline \multicolumn{5}{|c|}{1998 Baseline group $^{a}$} \\
\hline Minnesota & 12 & 0 & $0.04(0.02)^{\mathrm{b}}$ & $0.01-0.08$ \\
\hline Nebraska & 14 & 0 & $0.03(0.01)$ & $0.02-0.05$ \\
\hline North Dakota & 1 & 0 & 0.03 & \\
\hline Colorado & 1 & 0 & 0.09 & \\
\hline Idaho & 2 & 0 & $0.05(0.01)$ & $0.04-0.05$ \\
\hline South Dakota & 1 & 0 & 0.03 & \\
\hline Texas & 1 & 0 & 0.03 & \\
\hline \multicolumn{5}{|c|}{1998 Nonbaseline group ${ }^{c}$} \\
\hline Minnesota & 14 & $2-3$ & $0.04(0.02)$ & $0.02-0.08$ \\
\hline Nebraska & 3 & $2-3$ & $0.04(0.01)$ & $0.03-0.04$ \\
\hline North Dakota & 2 & $2-3$ & $0.04(0.01)$ & $0.04-0.05$ \\
\hline Wisconsin & 2 & $0-1$ & $0.04(0.02)$ & $0.04-0.06$ \\
\hline \multicolumn{5}{|l|}{1999 Group } \\
\hline Minnesota & 8 & $6-8$ & $0.07(0.08)$ & $0.03-0.25$ \\
\hline North Dakota & 3 & $6-8$ & $0.04(0.00)$ & $0.03-0.04$ \\
\hline \multicolumn{5}{|l|}{2000 Group } \\
\hline Nebraska & 3 & $12-16$ & $2.37(0.24)$ & $2.10-2.55$ \\
\hline North Dakota & 10 & $9-11$ & $0.04(0.01)$ & $0.03-0.05$ \\
\hline \multicolumn{5}{|l|}{2001 Group } \\
\hline Minnesota & 8 & $13-14$ & $2.91(0.35)$ & $2.45-3.35$ \\
\hline Nebraska & 76 & $15-18$ & $2.28(0.47)$ & $0.51-2.85$ \\
\hline North Dakota & 19 & $13-14$ & $2.43(1.13)$ & $0.03-3.40$ \\
\hline
\end{tabular}

a Isolates collected in subsequent years were not necessarily collected from the same sites as baseline isolates.

b Values in parentheses denote standard deviation.

${ }^{c}$ Isolates of $A$. solani collected after azoxystrobin received emergency registration in $1998(\sim 7 / 30 / 98)$ in North Dakota, Nebraska, Minnesota, and Wisconsin.

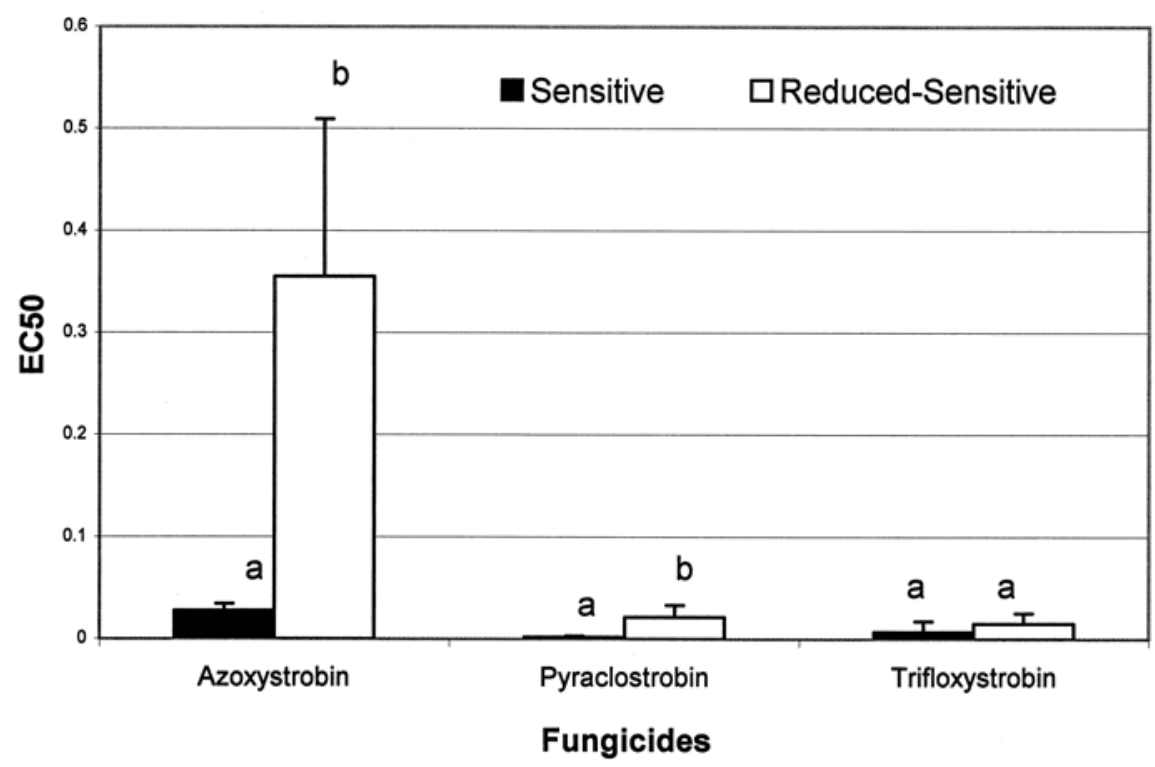

Fig. 2. Mean $\mathrm{EC}_{50}$ values (effective fungicide concentration that inhibited spore germination by $50 \%$ ) for sensitive and reduced-sensitive Alternaria solani isolates obtained from the in vitro crosssensitivity assessment of azoxystrobin, pyraclostrobin, and trifloxystrobin. Mean separation provided by Student's $t$ tests $(P=0.05)$. Within fungicides, columns with the same letter are not significantly different. Vertical bars indicate standard deviation for all tests performed on each isolate group. early blight disease. These three isolates had $\mathrm{EC}_{50}$ values of $0.028,0.037$, and 0.041 $\mu \mathrm{g} / \mathrm{ml}$, within the range of baseline $\mathrm{EC}_{50}$ values reported in this study.

In vitro cross-sensitivity assessment. Highly significant differences $(P=0.001)$ were detected between the two isolate groups, sensitive and reduced-sensitive, among the three fungicides. The mean $\mathrm{EC}_{50}$ of the azoxystrobin reduced-sensitive isolates were nearly 13 -fold and 10 -fold higher than A. solani isolates sensitive to azoxystrobin and pyraclostrobin, respectively, resulting in significant differences between the two isolate groups in response to these two $\mathrm{Q}_{0} \mathrm{I}$ fungicides (Fig. 2). The shift in sensitivity to trifloxystrobin between sensitive and reduced-sensitive $A$. solani isolates was only twofold and not significant, resulting in a significant isolate group $\times$ fungicide interaction $(P=0.0001)$.

Correlation of $\mathrm{EC}_{50}$ values for isolates exposed to azoxystrobin and pyraclostrobin were strong and highly significant (Fig. 3A). Correlations between $\mathrm{EC}_{50}$ values for azoxystrobin and trifloxystrobin (Fig. 3B) and between $\mathrm{EC}_{50}$ values for trifloxystrobin and pyraclostrobin were also significant but not as strong (Fig. 3C).

Effect of isolate sensitivity to $Q_{0} I$ fungicides on disease control. Levene's test for homogeneity of variance indicated that among the 225 variances estimated (five isolates $\times$ three fungicides $\times$ five fungicide concentrations $\times$ three trials), all but 18 were homogeneous, and therefore data were combined for further analysis.

There were significant differences in disease control among the fungicides at all fungicide concentrations except $0.1 \mu \mathrm{g} / \mathrm{ml}$ $(P>0.05)$ (Fig. 4). Dose response curves indicate that sensitive $A$. solani isolates were controlled similarly at concentrations of $1.0,10.0$, and $100.0 \mu \mathrm{g} / \mathrm{ml}$ azoxystrobin and pyraclostrobin, which was substantially higher than the control provided by trifloxystrobin (Fig. 4). For all fungicides, disease control of reduced-sensitive isolates of A. solani was significantly less than the control provided by azoxystrobin and pyraclostrobin on sensitive isolates (Fig. 4). At higher fungicide concentrations $(10.0$ and $100.0 \mu \mathrm{g} / \mathrm{ml})$ disease control of reduced-sensitive isolates with pyraclostrobin was significantly greater than disease control provided by azoxystrobin (Fig. 4). The amount of disease control provided by trifloxystrobin was not significantly different for sensitive and reduced-sensitive $A$. solani isolates at any concentration (Fig. 4).

\section{DISCUSSION}

$\mathrm{Q}_{\mathrm{o}} \mathrm{I}$ fungicides are inhibitors of spore germination (10); therefore, a spore germination assay was developed to determine the baseline sensitivity of $A$. solani to azoxystrobin, pyraclostrobin, and trifloxystrobin. It has been suggested that in vitro spore germination assays cannot be used to 
determine sensitivities of fungal pathogens to these chemistries $(9,16)$ and that in vivo assays are much more sensitive. In vitro spore germination assays have been successfully utilized (1), however, and it is apparent from the data reported here that in vitro spore germination assays were sufficiently sensitive to detect shifts in sensitivity to $\mathrm{Q}_{0} \mathrm{I}$ fungicides in $A$. solani. Initial studies performed by our laboratory demonstrated approximately a 100-fold shift in mean $\mathrm{EC}_{50}$ values between azoxystrobin sensitive $(0.011$ to $0.091 \mu \mathrm{g} / \mathrm{ml})$ and azoxystrobin reduced-sensitive isolates (1.45 to $3.40 \mu \mathrm{g} / \mathrm{ml}$ ). However, with improved technique development during our studies, including the omission of Tween 20 , and the drying and parafilming of the petri plates, we now know that the sensitiv-
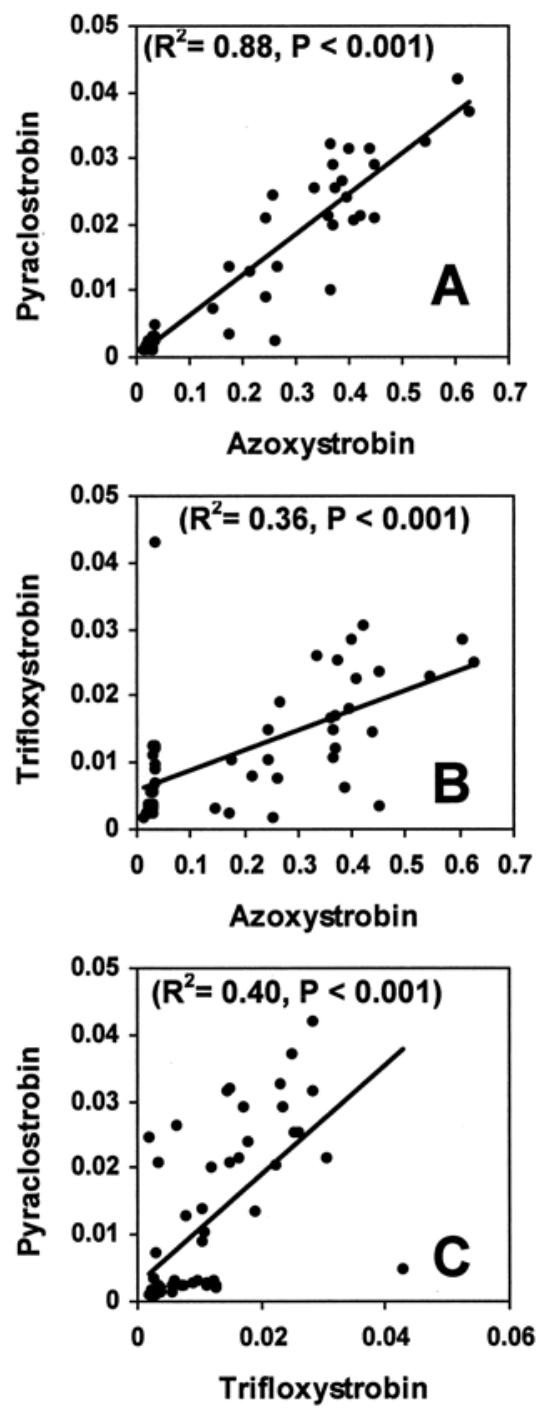

Fig. 3. Relationship between $\mathbf{A}$, in vitro azoxystrobin and pyraclostrobin sensitivity, $\mathbf{B}$, in vitro azoxystrobin and trifloxystrobin sensitivity, and $\mathbf{C}$, in vitro trifloxystrobin and pyraclostrobin sensitivity of the 54 Alternaria solani isolates tested in the cross-sensitivity assessment. $\mathrm{X}$ and $\mathrm{Y}$ axes represent mean $\mathrm{EC}_{50}$ values (effective fungicide concentration that inhibited spore germination by $50 \%$ ) in $\mu \mathrm{g} / \mathrm{ml}$ for the respective fungicides. ity of the baseline population is much more narrow $(0.019$ to $0.036 \mu \mathrm{g} / \mathrm{ml})$ and that the shift in sensitivity within the azoxystrobin reduced-sensitive $A$. solani population is of much less magnitude, approximately 10 -fold $(0.145$ to $0.625 \mu \mathrm{g} / \mathrm{ml})$. With the use of an in vitro spore germination assay, we report here the first shift in sensitivity to $Q_{0} I$ fungicides of a fungal plant pathogen with only an anamorphic stage and no known teleomorphic stage. To our knowledge, this is the first full report of a plant pathogen with no known sexual cycle developing resistance or reducedsensitivity to $\mathrm{Q}_{\mathrm{O}} \mathrm{I}$ chemistry (11).

The in vitro spore germination assay used in these studies was also sensitive enough to detect cross-sensitivity of the three $\mathrm{Q}_{\mathrm{o}} \mathrm{I}$ fungicides investigated. It was interesting to note that baseline $A$. solani isolates were nearly 10 times more sensitive to pyraclostrobin and trifloxystrobin than they were to azoxystrobin, which supports the use of in vitro spore germination assays to successfully monitor populations for resistance development in A. solani. However, the greater intrinsic activity of pyraclostrobin on $A$. solani compared with azoxystrobin has not translated into increased disease control in the field. Previously conducted field experiments have demonstrated no difference in disease control between pyraclostrobin and azoxystrobin on sensitive isolates, while both fungicides were superior to trifloxystrobin
(N. C. Gudmestad, unpublished). Clearly, intrinsic activity alone is not an adequate means to assess relative fungicide efficacy, as has been previously discussed with other $\mathrm{Q}_{0} \mathrm{I}$ fungicides $(16,17)$.

Cross-sensitivity tests demonstrated that isolates with reduced-sensitivity to azoxystrobin also possess reduced-sensitivity to trifloxystrobin and pyraclostrobin, despite the fact that these fungicides were not registered on potato until 2001 and 2002, respectively. The relationship of crosssensitivity between azoxystrobin and pyraclostrobin is much stronger than it is between trifloxystrobin and either of the other two $\mathrm{Q}_{\mathrm{O}} \mathrm{I}$ fungicides. This may be due to the fact that azoxystrobin and pyraclostrobin are more closely related $\mathrm{Q}_{\mathrm{O}} \mathrm{I}$ fungicides and have been classified by the Fungicide Resistance Action Committee (FRAC) (information available online) into the methoxy-acrylate and methoxycarbamate groups, respectively, while trifloxystrobin belongs to the oximinoacetate group. Additionally, the relationships between in vitro sensitivity of the sensitive and reduced-sensitive $A$. solani isolates to each $\mathrm{Q}_{\mathrm{o}} \mathrm{I}$ fungicide is reflected in the results of the in vivo studies. Azoxystrobin and pyraclostrobin provided similar levels of control of early blight disease caused by sensitive $A$. solani isolates, which was significantly superior to the control provided by trifloxystrobin, consistent with the aforementioned results in the

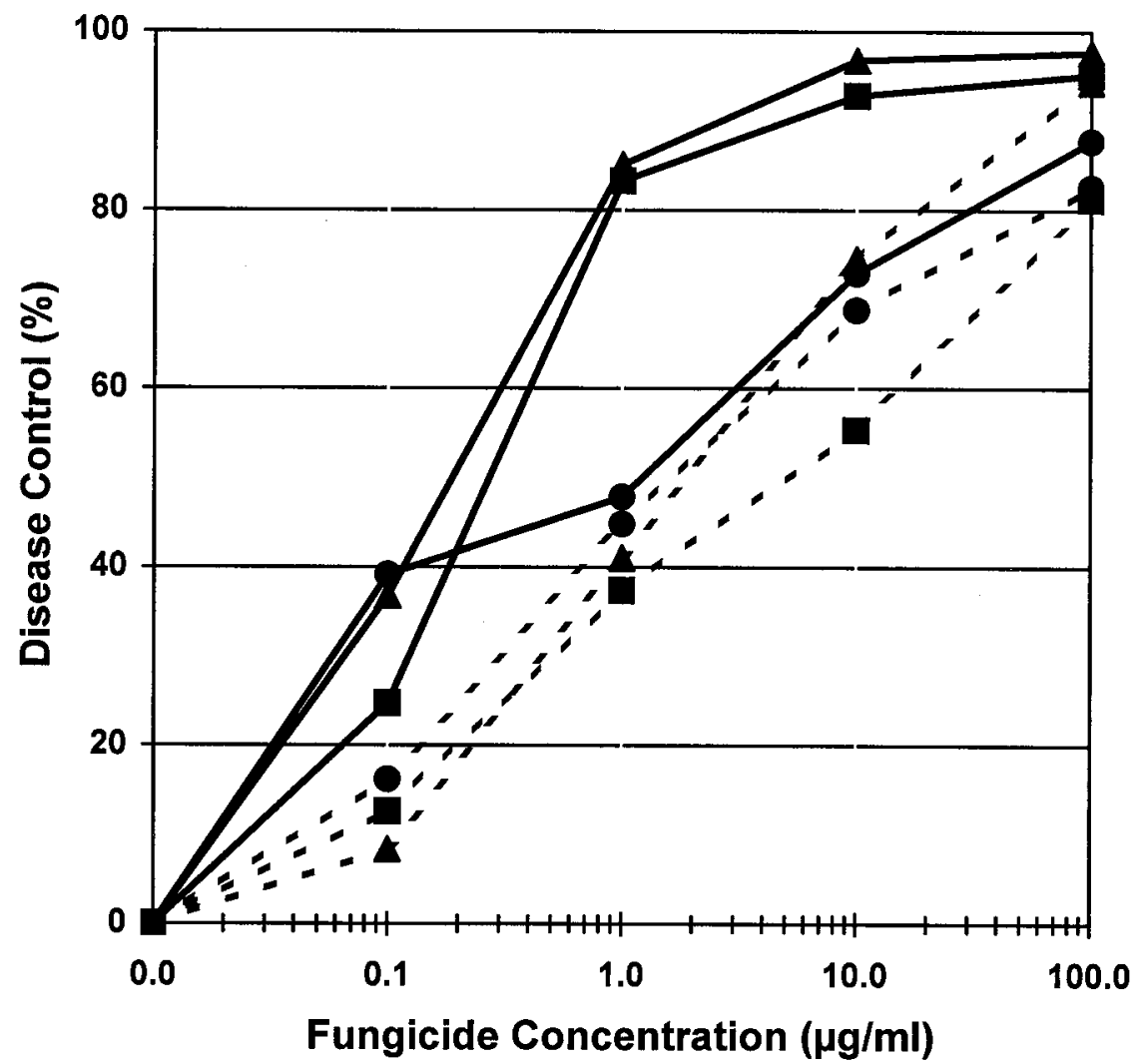

Fig. 4. Mean in vivo percent disease control for two sensitive $(-)$ and three reduced-sensitive (---) isolates of Alternaria solani to azoxystrobin $(\mathbf{\square})$, pyraclostrobin $(\mathbf{A})$, and trifloxystrobin $(\bullet)$ at each fungicide concentration. 
field (N. C. Gudmestad, unpublished). Azoxystrobin and pyraclostrobin provided significantly less control of disease caused by $A$. solani isolates with reducedsensitivity to azoxystrobin compared with the level of control of disease caused by sensitive isolates. However, at higher concentrations, pyraclostrobin consistently had an advantage in controlling disease caused by reduced-sensitive isolates, perhaps due to its greater intrinsic activity. The shift in sensitivity was less pronounced in vitro with trifloxystrobin, and these results are reflected also in the in vivo studies. Disease control of reducedsensitive isolates provided by trifloxystrobin was not significantly different than the level of control this fungicide provided for sensitive isolates.

We have been careful in our choice of terminology in reference to the shift in sensitivity of $A$. solani to $\mathrm{Q}_{\mathrm{o}} \mathrm{I}$ fungicides. In this specific case, we prefer to use the term "reduced-sensitivity" rather than resistance to reflect the shift in sensitivity. For example, in vivo assays performed demonstrated approximately a 40 to $50 \%$ loss of early blight disease control at 1.0 $\mu \mathrm{g} / \mathrm{ml}$ when using azoxystrobin and pyraclostrobin compared with the level of disease control of a sensitive population at the same fungicide concentration. In our view, resistance to this fungicide class would equate to a $100 \%$ loss of disease control, at every concentration we tested, rendering the fungicide of no value to the potato producer. However, from the data reported here, the shift in sensitivity we detected does not result in a total loss of disease control, hence the use of the term "reduced-sensitivity" to describe the shift in sensitivity of the $A$. solani population in response to $\mathrm{Q}_{\mathrm{O}} \mathrm{I}$ chemistry.

Resistance to $\mathrm{Q}_{\mathrm{O}} \mathrm{I}$ fungicides has been reported previously in a number of plant pathogens. The cytochrome $b$ gene has been sequenced for a number of these $\mathrm{Q}_{0} \mathrm{I}$ resistant plant pathogenic fungi, including Venturia inaequalis (18), Erysiphe (Blumeria) graminis f. sp. tritici (14), Pyricularia (Magnaporthe) grisea (7), Pseudoperonospora cubensis (6), Podosphaera fusca (6), and Mycosphaerella fijiensis (13). Comparing the DNA sequence of sensitive and $\mathrm{Q}_{\mathrm{O}} \mathrm{I}$-resistant isolates of E. graminis, $P$. cubensis, $P$. fusca, and $M$. fijiensis revealed a single-point mutation leading to an amino acid change at position 143 from glycine $(\mathrm{G})$ to alanine (A). Interestingly, six $\mathrm{Q}_{\mathrm{o}} \mathrm{I}$-resistant isolates of $P$. grisea were found to possess the G143A mutation, while two isolates, which were not fully resistant to $Q_{0} I$ fungicides in vivo, possessed a mutation resulting in an amino acid change at position 129 from phenylalanine $(\mathrm{F})$ to leucine (L) (7,15). From the $180 \mathrm{~A}$. solani isolates tested for sensitivity to azoxystrobin in this study, six isolates (521-1, 521-2, 523, 526-1, 526-2, 815-B) collected in 2001 and one baseline isolate (13-1) collected in 1998 prior to commercial use of azoxystrobin had the cytochrome $b$ gene sequenced by researchers at Syngenta Crop Protection. None of the isolates tested had undergone the G143A mutation. However, all six isolates collected in 2001 had undergone the F129L mutation, while the baseline isolate had not (G. Olaya, Syngenta Crop Protection, personal communication). As observed with $P$. grisea (15), these isolates are not totally resistant to $\mathrm{Q}_{\mathrm{o}} \mathrm{I}$ fungicides in vivo, which supports our reference to the shift in sensitivity to azoxystrobin in $A$. solani as reducedsensitivity rather than resistance. A. solani may be the only plant pathogenic fungus reported to date in which a disruptive shift in sensitivity is due solely to the F129L mutation rather than the G143A mutation. Interestingly, cross-sensitivity between $\mathrm{Q}_{0} \mathrm{I}$ fungicides (azoxystrobin, kresoximmethyl, trifloxystrobin) and other $\mathrm{Q}_{\mathrm{O}} \mathrm{I}$ fungicides such as famoxadone and fenamidone has been reported with a number of plant pathogenic fungi possessing the G143A mutation $(1,4)$. We do not know if $\mathrm{Q}_{\mathrm{o}} \mathrm{I}$ reduced-sensitive isolates of $A$. solani possessing the F129L mutation are crosssensitive with famoxadone and fenamidone, but those studies are warranted since registration of these $\mathrm{Q}_{\mathrm{o}} \mathrm{I}$ fungicides on potato is pending with the EPA.

We also do not know the extent to which the shift in $\mathrm{Q}_{\mathrm{o}} \mathrm{I}$ sensitivity in A. solani has occurred in other regions of the United States. Isolates in our collection were recovered primarily from the north central United States, from North Dakota to Nebraska. Early blight disease pressure in midwestern potato production areas is high primarily because of the frequent formation of dew at night. Dew formation, which provides the alternating wet and dry periods necessary for conidial formation, provides an environment that is generally conducive for disease development and hence frequent fungicide application. The shift in sensitivity of $A$. solani to azoxystrobin occurred within the first 2 years of use in the Upper Midwest, and occurred in potato fields in which the early blight fungus was exposed to approximately 12 to 16 azoxystrobin applications.

The first field observation suggesting a lack of early blight disease control with azoxystrobin was made by one of the authors in potato fields in an isolated potato production area of Nebraska during the summer of 2000. In these specific cases, five to six applications of azoxystrobin had been made to potato fields in that production area over the course of each of the 1999 and the 2000 growing seasons (10 to 12 total azoxystrobin exposures), with six being the maximum number of applications allowed by the label per growing season. Fungicide records maintained by the grower indicated that label recommendations were never compromised; i.e., no sequential applications, rotation with other fungicide chemistries, and full label rates used during each application (113 g a.i./ha). However, we cannot discount the possibility that the Section 18 emergency exemption for azoxystrobin that EPA granted four states in 1998 (Nebraska, North Dakota, Minnesota, Wisconsin) may also have played a detrimental role in the development of reduced-sensitivity in $A$. solani to this chemistry. Applications of azoxystrobin were made during the latter one-third of the growing season (after 30 July) to a potato crop in which early blight disease pressure was extremely high, hence the Section 18 request. Resistance management strategies frequently recommend that fungicides be applied preventatively, and the applications made to the potato crop late in the 1998 growing season were not consistent with this recommendation. Nonetheless, as a result of this disruptive shift in sensitivity to $\mathrm{Q}_{\mathrm{O}} \mathrm{I}$ fungicides in A. solani, a significant tool in the management of early blight on potato has been seriously compromised. Since $\mathrm{Q}_{0} \mathrm{I}$ fungicides represent a premium-priced fungicide group, where the cost of the chemical was justified initially by the excellent early blight disease control that was derived from their use, it is now questionable whether or not the loss of efficacy in certain areas of the north central United States due to the presence of reduced-sensitive A. solani isolates can further justify their use. Potato producers in the Midwest, where early blight disease pressure is high, may be forced to more closely evaluate cost:benefit ratios before they apply a $\mathrm{Q}_{0} \mathrm{I}$ fungicide in situations where early blight represents their only significant foliar disease.

\section{ACKNOWLEDGMENTS}

We thank Curt Doetkott for statistical consultation, Gilberto Olaya and Amy Holm (Syngenta Crop Protection) for technical assistance and advice, Kylie Rodrigez and Aarnes Gudmestad for assistance in performing laboratory assays, and Dean Peterson for assistance in performing greenhouse assays.

\section{LITERATURE CITED}

1. Chin, K. M., Wirz, M., and Laird, D. 2001 Sensitivity of Mycosphaerella fijiensis from banana to trifloxystrobin. Plant Dis. 85:12641270.

2. Christ, B. J. 1991. Effect of disease assessment method on ranking potato cultivars for resistance to early blight. Plant Dis. 75:353-356.

3. Harrison, M. D., and Venette, J. R. 1970 Chemical control of potato early blight and its effect on potato yield. Am. Potato J. 47:81-86.

4. Heaney, S. P., Hall, A. A., Davies, S. A., and Olaya, G. 2000. Resistance to fungicides in the QoI-STAR cross resistance group: Current perspectives. Pages 755-762 in: Brighton Crop Protection Conference-Pests and Diseases2000. Vol. 2. Major Print, Nottingham, UK.

5. Holm, A. L. 2000. Sensitivity of Alternaria spp. to foliar fungicides. M.S. thesis. North Dakota State University, Fargo.

6. Ishii, H., Fraaije, B. A., Sugiyama, T., Noguchi, K., Nishimura, K., Takeda, T., Amano, T., and Hollomon, D. W. 2001. Occurrence and 
molecular characterization of strobilurin resistance in cucumber powdery mildew and downy mildew. Phytopathology 91:1166-1171.

7. Kim, Y.-S., Dixon, E. W., Vincelli, P., and Farman, M. L. 2003. Field resistance to strobilurin $\left(\mathrm{Q}_{0} \mathrm{I}\right)$ fungicides in Pyricularia grisea caused by mutations in the mitochondrial cytochrome b gene. Phytopathology 93:891-900.

8. Milliken, G. A., and Johnson, D. E. 1992. Oneway treatment structure in a completely randomized design with heterogeneous errors. Pages 16-28 in: Analysis of Messy Data. Vol. I: Designed Experiments. Chapman and Hall, London, UK.

9. Olaya, G., and Köller, W. 1999. Baseline sensitivities of Venturia inaequalis populations to the strobilurin fungicide kresoxim-methyl. Plant Dis. 83:274-278.

10. Olaya, G., Zheng, D., and Köller, W. 1998. Differential responses of germinating Venturia inaequalis conidia to kresoxim-methyl. Pestic. Sci. 54:230-236.

11. Pasche, J. S., Wharam, C. M., and Gudmestad, N. C. 2002. Shift in sensitivity of Alternaria solani (potato early blight) to strobilurin fungicides. Pages 841-846 in: Brighton Crop Protection Conference-Pests and Diseases2002. Vol. 2. Mafor Print, Nottingham, UK.

12. Pscheidt, J. W., and Stevenson, W. P. 1988. The critical period for control of early blight (Alternaria solani) of potato. Am. Potato J. 65:425-438.

13. Sierotzki, H., Parisi, S., Steinfeld, U., Tenzer, I., Poirey, S., and Gisi, U. 2000. Mode of resistance to respiration inhibitors at the cytochrome $\mathrm{bc}_{1}$ enzyme complex of $\mathrm{Myco}$ sphaerella fijiensis field isolates. Pest Manag. Sci. 56:833-841.

14. Sierotzki, H., Wullschleger, J., and Gisi, U. 2000. Point-mutation in cytochrome b gene conferring resistance to strobilurin fungicides in Erysiphe graminis f. sp. tritici field isolates. Pestic. Biochem. Physiol. 68:107-112.

15. Vincelli, P., and Dixon, E. 2002. Resistance to $\mathrm{Q}_{\mathrm{o}} \mathrm{I}$ (strobilurin-like) fungicides in isolates of Pyricularia grisea from perennial ryegrass. Plant Dis. 86:235-240.

16. Wong, F. P., and Wilcox, W. F. 2000. Distribution of baseline sensitivities to azoxystrobin among isolates of Plasmopara viticola. Plant Dis. 84:275-281.

17. Wong, F. P., and Wilcox, W. F. 2002. Sensitivity to azoxystrobin among isolates of Uncinula necator: Baseline distribution and relationship to myclobutanil sensitivity. Plant Dis. 86:394-404.

18. Zheng, D., and Köller, W. 1997. Characterization of the mitochondrial cytochrome $b$ gene from Venturia inaequalis. Curr. Genet. 32:361-366. 